\title{
EL PALACIO DE ANGLONA: UN ILUSTRE DESCONOCIDO
}

\author{
Maria José Arnáiz Gorroño, Historiadora \\ Enrique Gutiérrez de Calderón Gómez
}

Entre calles "costaneras", vecino a la torre mudéjar de San Pedro y rodeado, en otros tiempos, por las residencias principales de la Corte, se encuentra el Palacio de Anglona, disfrazado de abandono. Poco elocuentes fueron -incluso en sus momentos de esplendor- los palacios madrileños, que necesitaban "maquillarse" a la hora de celebraciones... Esta falta de representatividad en las fachadas, se suplia con sofisticados interiores. $Y$ estos interiores se volcaban hacia la calle, en una rivalidad dinástica tan fuerte como la que en Cáceres o San Giminiano evidencian sus construcciones.

Tenemos noticia del Palacio de Anglona, desde el siglo XVI, cuando no era tal palacio ni pertenecia al Principe de Anglona. Una serie de construcciones irregulares, en torno a un patio -de labranza-, pertenecientes a los Vargas (como tantas otras construcciones de la zona), acabarán regularizando la manzana en una gran casapalacio, con no menos ilustres moradores: Osuna, de la Romana, etc.

La famosa condesa-duquesa, Doña Maria Josefa de la Soledad Alonso-Pimentel..., inspiradora del "capricho" (experiencia fisiocrática de la Alameda de Osuna) contraerá matrimonio en 1771, en el oratorio de la casa.

El primogénito de los IX duques de Osuna, el marqués de Peñafiel, celebrará su matrimonio en esta mansión que, posteriormente, heredará su hermano. Para este evento se renueva el edificio a la moda de la época (como explican los profesores Luna y Bonet) y se realiza una operación regularizadora de la manzana, con el cierre de la crujia sur, para dependencias auxiliares, para ello se cuenta con Antonio López Aguado, más preocupado por temas compositivos que de los de indole constructiva; asi un conjunto desordenado (número de plantas, huecos, anchos de crujias, lineas de cumbreras, etc.) aprovechando en algún momento cimentaciones anteriores (puede que alguna mudéjar) se convierte en un potente edificio de fria regularidad neoclásica.

Los cambios producidos por las sucesivas adiciones, alteraciones en la situación de los huecos, divisiones interiores que realizan sus distintos inquilinos, etc. motivan un agotamiento mecánico y una debilitación de las fábricas al cambiar las solicitaciones de sus elementos resistentes.

Estos problemas que aparecen a lo largo del siglo XVIII, a los que se suman los producidos por la misma implantación del edificio (sobre una torrentera y con cimentaciones diferentes) no se abordan de una manera global.

En el siglo XIX se acomete una segunda reforma al adquirirlo en 1872 los marqueses de la Romana, que vuelve a incidir especialmente, en aspectos decorativos, entre los que destaca la gran escalera principal tardo-neoclásica, y los

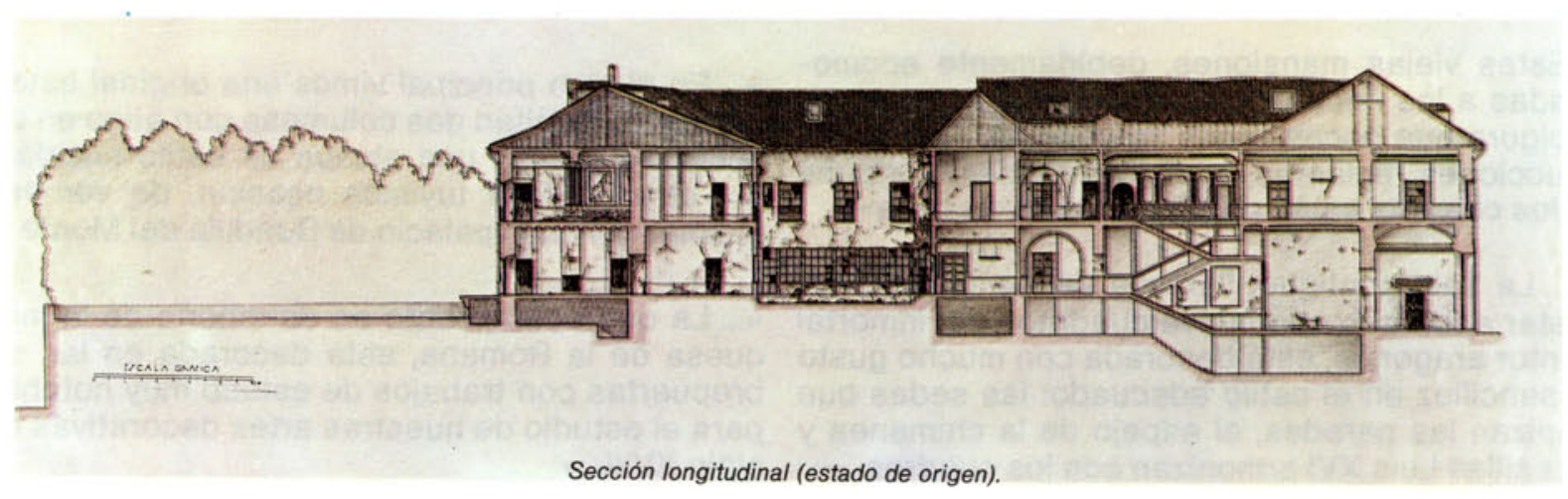




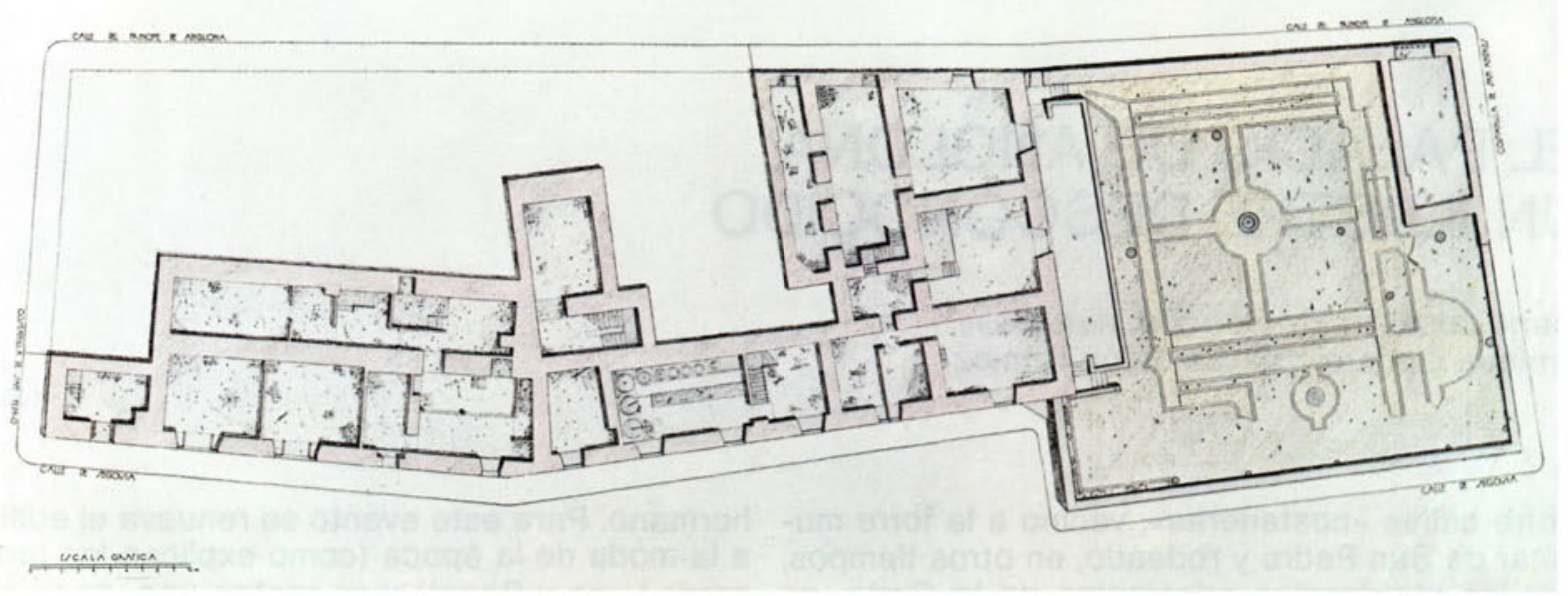

Planta sótano (estado de origen).

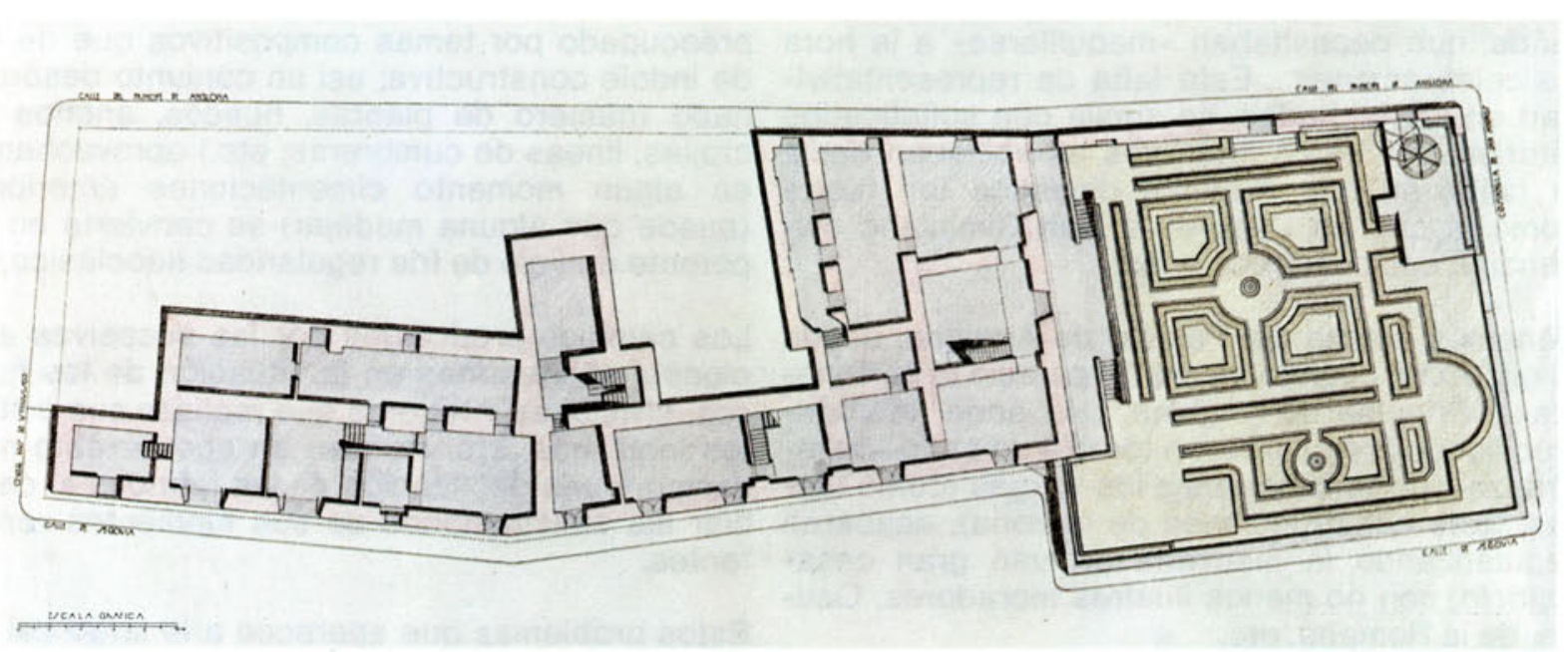

Planta sótano (estado reformado).

salones de la planta primera (en la crujia principal a la calle de Segovia) evocadores de los construidos en el siglo anterior.

Asi describe José Peñuelas la casa de los marqueses de la Romana, que "a la vista de los tejados escalonados nos traslada momentáneamente lejos de una urbe moderna", que era Madrid en 1926.

"Estas viejas mansiones, debidamente acomodadas a las necesidades modernas, son de una holgura que pocas veces se encuentra en construcciones recientes, y alli los muebles antiguos y los cuadros están propiamente en su casa".

“... La sala contigua, llamada de los Goyas, por estar adornada con nueve cuadritos del inmortal pintor aragonés, está decorada con mucho gusto y sencillez en el estilo adecuado: las sedas que tapizan las paredes, el espejo de la chimenea y las sillas Luis XVI armonizan con los cuadros..."
"... No es cosa de que describamos aqui las pinturas, tan conocidas algunas, como el delicioso cuadrito "la Maja y el Petimetre". En estas obras se muestra el genio vario de Goya, tan pronto brusco como delicado y siempre enamorado de la luz y del color..."

«.. A continuación pasamos al llamado salón de baile..."

"... En el piso principal vimos una original estancia, en cuya mitad dos columnas con ático en semicirculo forman una alcoba de estilo neoclásico; otra análoga tuvimos ocasión, de ver este mismo año en el palacio de Boadilla del Monte..."

"... La que actualmente es dormitorio de la marquesa de la Romana, está decorada en las sobrepuertas con trabajos de estuco muy notables para el estudio de nuestras artes decorativas del siglo XVIII..." 


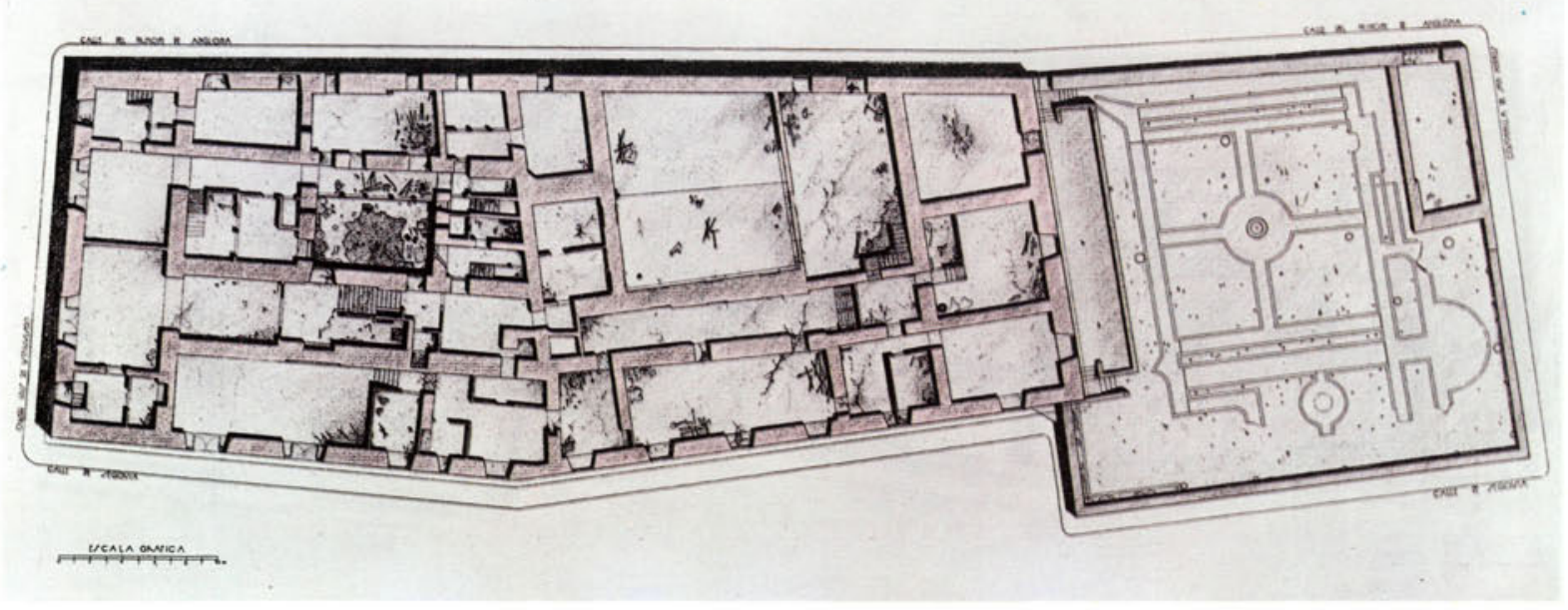

Planta baja (estado de origen),

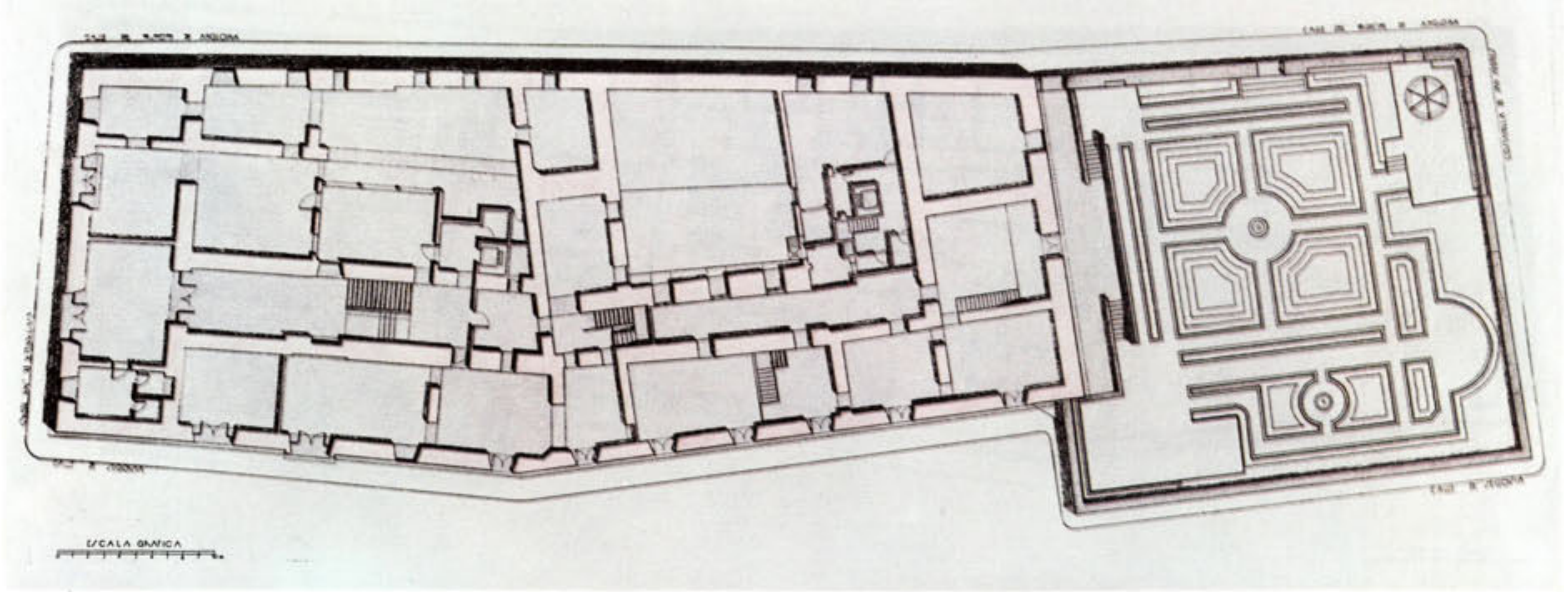

Planta baja (estado reformado).

“... Tales son, a grandes rasgos, las cosas más sobresalientes que observamos en la visita al palacio de los marqueses de la Romana, y al terminar nuestra reseña hacemos presente al marqués, que amablemente nos recibió y fue dando noticias de sus colecciones artisticas, las más expresivas gracias."

El palacio es habitado por la casa de la Romana hasta la guerra civil española. Durante el paréntesis que supone la guerra se produce un cambio de uso (se utiliza como cárcel) con el consiguiente deterioro de sus interiores y abandono final.

En 1942 los marqueses de la Romana tras desestimar nueva ocupación del palacio, lo alquilan a las autoridades municipales que lo convierten en sección de Estadistica, Empadronamiento y Alcantarillado del Excmo. Ayuntamiento de Madrid. Con una renta contractual de 50.000 ptas. al año, que en 1977 es de 13.750 ptas. al trimes- tre (55.000 ptas. al año), el Ayuntamiento decide abandonar el edificio por la situación de ruina del inmueble.

"Los servicios municipales de Estadistica y Alcantarillado han sido los últimos en ocupar el inmueble, habiéndose desalojado como consecuencia del estado ruinoso del mismo...

Sobre la conveniencia de adquisición del inmueble, aparte dificultades de carácter económico, debe señalarse que el mismo se encuentra sometido a la Ordenación Especial del Barrio Histórico, con limitaciones en cuanto a su aprovechamiento." (informe municipal de 30 de abril de 1977).

Un año más tarde, el 5 de abril de 1978 , otro informe municipal (del departamento de Hacienda, sección de Patrimonio) acuerda "rescindir el contrato de arrendamiento... referente a la finca n.o 13 de la calle de Segovia, donde han estado 

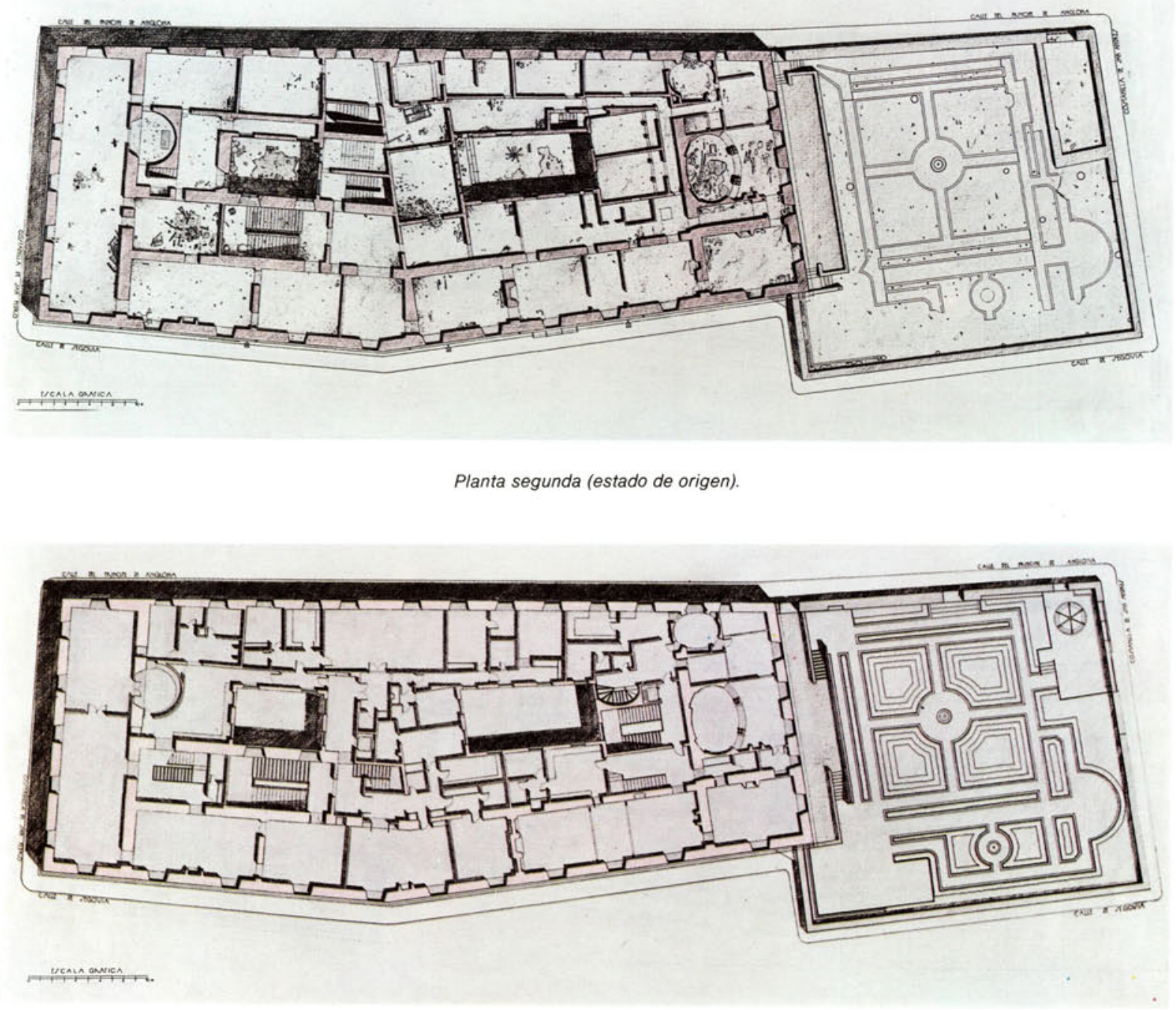

Planta segunda (estado reformado).

instalados los servicios de Estadistica Municipal, trasladados a su nueva sede como consecuencia del estado ruinoso del inmueble".

Será en 1981 (según escrito de la Gerencia Municipal de Urbanismo del 10 de diciembre del citado año, ref. RG18089/80 H-71/80 DEN) cuando se notifica a la propiedad la necesidad de comenzar las obras necesarias para dejar el edificio en las debidas condiciones de seguridad "ya que se ha comprobado: mal estado generalizado de toda la edificación comprendida entre los dos patios interiores, incluidos los cerramientos a ambos patios. Asi, en esta zona se encuentran trozos de forjados caidos y otras grandes flechas debido a la pudrición de las viguetas de madera. Rotura de diversos muros de carga por diversas causas, aplastamiento y disgregación de fábricas, cedimientos, etc... La causa radica en los desperfectos de cubierta que permiten abundantes vias de agua y en las redes de evacuación de aguas tanto vertical como horizontal.
En el vestibulo de entrada se aprecian reventamientos en los machos de fábrica a ambos lados del paso de enlace con la escalera principal... en el cuarto situado a la derecha del vestibulo de entrada el forjado que cubre la planta de acceso tiene una serie de viguetas rotas lo cual ha puesto en carga el tabique inferior, lo que a su vez motiva flecha excesiva e inminente rotura del forjado interior. La cubierta del edificio ha sido dañada por incendio, habiendo sufrido diversas reparaciones de baja calidad constructiva, por lo cual es preciso reparar diversos elementos de entramado de madera: pares rotos, desencajados, hileras alabeadas o rotas, etc. Otras zonas del entramado y tabla de ripia se encuentran con trozos podridos por la humedad. Además, en general, es preciso el retejado del edificio con realización de caballetes, limas, sustitución de canalones y bajantes, reparación de lucernarios, etc. Las instalaciones del edificio están destrozadas en gran parte, o bien por desmantelamiento de las mismas o por deterioro por falta de mantenimiento". 
Con este panorama del palacio desahuciado la actual propiedad adquiere el edificio y decide acometer la rehabilitación del mismo, contra los malos augures que aconsejaban su demolición que hubiese supuesto una importante pérdida para el patrimonio histórico-artistico de Madrid.

Asi llegamos a los acuerdos de julio de 1984 (Ayuntamiento de Madrid, Gerencia Municipal) de Urbanismo, Departamento de Edificación, Licencia 5.341 NR 83/13206) para la rehabilita- ción total del edificio, consistente en: "consolidación de bóvedas y muros en planta sótano.

Reconstrucción y consolidación en el resto de las plantas, de la crujia a la calle Principe de Anglona de las que rodean los dos patios..."

Bajo la Dirección del Arquitecto Ignacio Blanco Lecroisey, dieron comienzo las obras de consolidación, con los apeos y demás medios auxiliares precisos.

\section{publicaciones del I.E.T.c.c.}

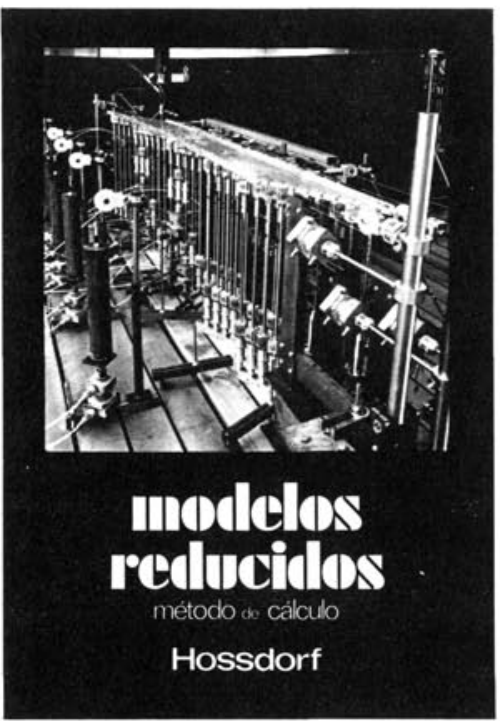

Modelos reducidos. Método de cálculo

H. Hossdorf, Ingeniero Civil

La técnica de los ensayos en modelos reducidos de estructuras sufre hoy dia una decisiva metamorfosis. Hasta hace poco era un medio más bien de artesania, que no siempre era tomado en serio por los académicos teorizantes dara comprender el comporta miento resistente de las estructuras complejas y al que se acudió las más de las veces, como a un ultimo remedio debido a sus indiscutibles insuficiencias. Sin embargo, en poco tiempo y gracias a su conexión con los ordenadores digitales, se ha trans formado en un instrumento cientificamente valioso, que no puede quedar a un lado en la práctica diaria del Ingeniero Proyectista.

Un volumen encuadernado en cartoné plastificado con lomo de tela, de $17 \times 24 \mathrm{~cm}$, compuesto de 250 páginas, 158 figuras y fotografias.

Precios: 1.800 ptas.; \$ USA 26.00

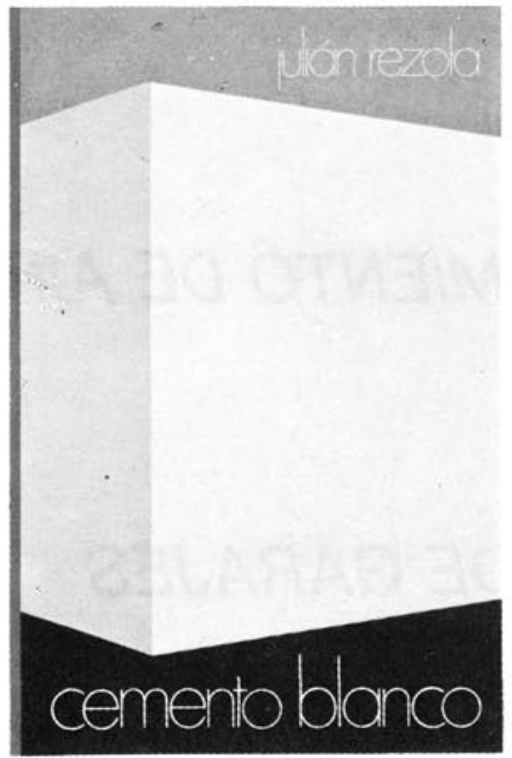

Cemento blanco

Julián Rezola

Ingeniero Quimico Dipl. I. Q. S

Sabido es que existe una extensa y documentada bibliografia sobre el cemento gris: en cambio, no puede decirse lo mismo acerca del cemento portland blanco, ya que los escritos existentes se refieren $\tan$ sólo a algunas peculiaridades que le distinguen de aquél.

El autor nos ofrece sus profundos conocimientos y su larga experiencia tanto en laboratorio como y su larga exper
en fabricación.

La parte descriptiva del libro se complementa con gráficos, diagramas y fotografias de gran utilidad, destinados a conseguir la aplicación apropiada de este aglomerante.

Un volumen encuadérnado en cartoné policerado, de $17.4 \times 24,3 \mathrm{~cm}$, compuesto de 395 páginas,
numerosas figuras, tablas y ábacos.

Precios: España, 1.700 ptas.; extranjero, \$ 24.

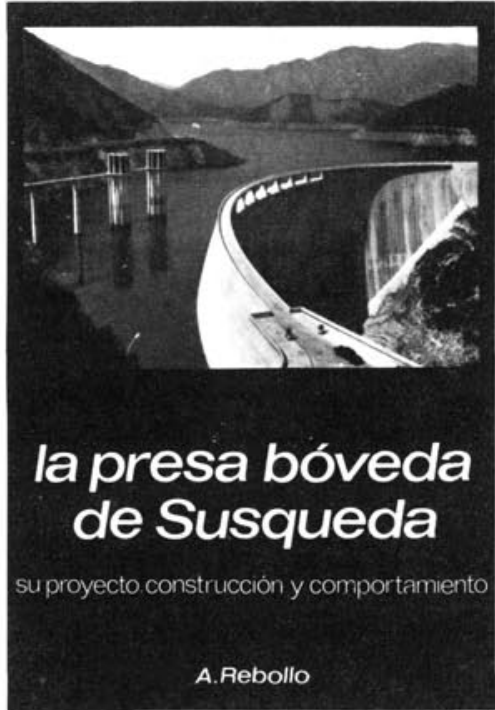

La presa bóveda de Susqueda

A. Rebollo,

Dr. Ingeniero de Caminos

El esfuerzo del constructor de presas se sitủa, por su pretensión de perennidad, a contracorriente de las tendencias de la civilización actual, caracte. rizada por lo fungible. Pueden evocarse las 10.000 grandes presas en funcionamiento o en construcción que están envejeciendo y reclaman los cuidados gerontológicos para mantener y perfeccionar su servicio y garantizar su inalienable pretensión de perennidad. En la medida en que todas nuevas obras, grandes o pequeñas, son portadoras de riesgos ecológicos $y$, a veces, catastróficos, que aumentan con el envejecimiento, la gerontologia de las presas es todo un emplazo. La acción adelantada de Arturo Rebollo en este terreno marca un camino a seguir para todos los que aman su propia obra con la devoción paternal que èl ha puesto en Susqueda.

Un volumen encuadernado en cartoné plastificado con lomo de tela, de 18 、 $24,5 \mathrm{~cm}$, compuesto de 408 páginas, 330 figuras y fotografias y 39 tablas.

Precios: 1.700 ptas.; extranjero, \$ USA 24.00 . 